\title{
Computational Analysis of Network Model Based Relationship of Mental Disorder with Depression
}

\author{
Md. Rakibul Hasan ${ }^{1}$, Bikash Kumar Paul 1,2,3 (D), Kawsar Ahmed 2,3,* (D), Shahin Mahmud ${ }^{4}$, Mithun Dutta ${ }^{5}$, \\ Md. Sazib Hosen ${ }^{6}$, Md. Mehedi Hassan ${ }^{7}$, Touhid Bhuyian ${ }^{1}$ (D)
}

1 Department of Software Engineering, Daffodil International University, Sukrabad, Dhanmondi, Dhaka 1205, Bangladesh

2 Department of Information and Communication Technology, Mawlana Bhashani Science and Technology University (MBSTU), Santosh, Tangail, 1902, Bangladesh

3 Group of Bio-photomatix, Mawlana Bhashani Science and Technology University (MBSTU), Santosh, Tangail 1902, Bangladesh

4 Department of Biotechnology and Genetic Engineering, Mawlana Bhashani Science and Technology University Santosh, Tangail, 1902, Bangladesh

5 Department of Computer Science and Engineering, Rangamati Science and Technology University, Vedvedi, Rangamati4500, Bangladesh

6 Jatio Mohila Sangstha, Ministry of Women and Children Affairs, Dhaka-1000, Bangladesh

7 Export Promotion Bureau, Commerce Ministry, Dhaka-1215, Bangladesh

* Correspondence: kawsar.ict@mbstu.ac.bd, k.ahmed.bd@ieee.org, kawsarit08050@gmail.com;

Scopus Author ID 34879354400

Received: 15.04.2020; Revised: 7.05.2020; Accepted: 8.05.2020; Published: 12.05.2020

\begin{abstract}
In this study, we present the network relationship of anxiety, eating and mood disorder with depression. Different computational network models have been demonstrated using different ongoing technologies. One of the most common mental illnesses can be classified as anxiety disorders. These are observable psychological conditions or a category of mental illnesses believed to be caused either by genetic weakness or by causes of environmental sensitivity. A wide range of psychological chronic conditions is often correlated with eating disorders (ED). However, the increasing role of lipid metabolism in ED pathogenesis has been highlighted by recent research studies. Depression (DE) acknowledgement is traced back to the ancient Greeks, who called it melancholia. The word depression has originated with the Greeks who used it to identify a specific condition, a God-given spiritual state, or a response involving rage or excitement, in different ways. Throughout drug research and development, finding innovative mechanisms is a massive challenge. In this field, structure-based design is a basic methodology and has become an essential part of developing drugs. The detailed threedimensional structure of the protein is shown for a significant number of drug targets. While simulation docking and similar biotechnology have progressed in recent times, a suitable set of docking simulations for simulation performance is difficult to identify.
\end{abstract}

Keywords: Mental disorder; Protein-protein interaction; Protein-drug interaction; Anxiety disorder; Eating disorder; Depression; Mood disorder.

Abbreviation: $\mathrm{NCBI}=$ National Center of Biotechnology Information; $\mathrm{AD}=$ Anxiety Disorder; $\mathrm{DE}=$ Depression; ED= Eating Disorder; $\mathrm{MD}=$ Mood Disorder; PPI = Protein-protein Interaction; $\mathrm{PDI}=$ Protein Drug Interaction; PCI = Protein Chemical Interaction.

(C) 2020 by the authors. This article is an open access article distributed under the terms and conditions of the Creative Commons Attribution (CC BY) license (https://creativecommons.org/licenses/by/4.0/).

\section{Introduction}

There are a wide number of problems with mental disorders, with different symptoms. We are described, however, by some mixture of irregular feelings, emotions, actions, and 
interactions with others. Most of these diseases could be treated successfully. Anxiety disorders (AD) are a category of mental disorders with severe anxiety and fear feelings. Anxiety is a concern for events in the future, and fear is a reaction to present events. These physical effects can cause physical symptoms, such as rapid heart rate and shakiness $[1,2]$. DE is a common disease of the mind. About 264 million people of all ages worldwide are suffering from DE [3]. DE is one of the world's leading causes of illness and a significant contributor to the worldwide disease burden. DE affects more women than men [3]. For moderate and severe DE, effective psychological and pharmacological interventions occur.

ED is a major health problem in Western countries and particularly among young people [4,5]. ED is very dynamic and lacks a pathophysiological description and is medically accepted by the specific clinical guidelines of the Fifth Edition of the Mental Disorders Diagnosis and Statistical Manual, published by the American Psychiatric Association [6]. Anxiety or mood disorders can be associated with ED; migraines; as well as physiological problems such as cardiac abnormalities, hormonal imbalances and a wide array of gastrointestinal (GI) symptoms [7]. Mood disorders (MD) are a set of psychiatric diseases that can impact one's emotional responses, energy and motivation at the same time [8]. MD can sometimes be linked to effective disorders. Psychiatrists began to recognize signs of mood disorders in infants, adolescents and adults during the 1980s [9].

Finding the characteristics of infection is important to understand the components of physiological and obsessive sickness procedures. It takes time to perform tests to confirm those characteristics linked to infection. Numerous analytical methods and tools have been developed to coordinate disease attributes in order to increase proficiency. Complex interactions among the different constituents of the cell, such as protein, DNA, RNA, and other small atoms, are effective in making Biological capabilities. The research work on screen has connected a framework for bioinformatics to create a model of performance and cooperation scheme by taking high-performance genomic and PPI data for AD, DE, ED and MD.

\section{Materials and Methods}

Bioinformatics has been applied in a limited number of previous research works involving the analysis of liable genes, the development of PPI networks, regulatory networks, and the possible interaction of drug proteins for specific 4 disorders. In this analysis, several steps are taken to achieve a better outcome. From information accumulation to the proteinchemical interaction network, some individual developments are made here. Figure 1 indicates the research methodology's graphical representation step by step. That phase is also listed below in the following subsections under 2.1 to 2.8 .

\subsection{Data collection.}

Bioinformatics software and utilities have very few reliable databases. AD, DE, ED and MD study results are gathered from the NCBI Gene database. The gene NCBI database is available for free and can be downloaded. Upon extracting responsible genes, it was reprocessed and screened for any further processing.

\subsection{Preprocessing.}

In the past, each of the features linked to $\mathrm{AD}, \mathrm{DE}, \mathrm{ED}$ and $\mathrm{MD}$ are collected. In this stage, just genes related to Homo sapiens are collected. They are primarily categorized and all 
other genes that are obtained are processed and only responsible genes that are responsible for human diseases are kept for the next process.

\subsection{Gene mining.}

The data mining technique is mainly used to produce appropriate data. Gene mining is among the most important areas of this research as any type of error can reject a substantial gene that occurs in the wrong outcome. Only the genes are extracted from the records of the sorted linkage genes. Afterward, genes are recognized and sorted in relation to each other. Using the intersection data mining method, the listed candidate genes linked to AD, DE, ED and MD were mined.

\subsection{Generic PPI.}

In bioinformatics, research into protein-protein interaction or PPI network plays a significant role. The PPI network often facilitates the knowledge of human disease genetic signaling pathways and the development of a new framework of disease pathways. Cytoscape is a very well-known and trusted bioinformatics research tool used to create PPI networks [10]. Targeted 4 diseases are developed from interconnected common genes of PPI networks and common pathways using Cytoscape in this process.

\subsection{Gene regulatory network.}

Gene regulation is a scientific term for a variety of concurrent processes, a well-known and well-understood one of which is encoding and translation, which controls the amount of gene expression and ultimately results in a specific number of the target protein. Regulators are most generally proteins, called transcription factors, but the general regulation often includes tiny molecules, such as RNAs and metabolites. Depending on the degree of abstract concept and accessibility of scientific information, there are different levels of gene network modeling [12].

\subsection{Protein drug interaction.}

Work on the interaction of protein drugs is of crucial importance in order to understand the fundamental characteristics of molecule affinity [13]. One way of resolving this, discrepancy is done by using computational methods to determine protein targets for a given drug molecule or to interact with drugs for specific protein targets [14]. Interaction with protein drugs is developed for all targeted 4 diseases ' interconnected, liable, prevalent genes.

\subsection{Protein chemical interaction.}

The portion of the biochemical environment that has been identified is that and a significant percentage of established protein-chemical relationships are becoming accessible for research studies. Protein - Chemical interaction data are spread across a wide variety of datasets and literature, making it difficult to evaluate the known relationships of any significant chemicals [15]. Co-expression networks are transcript-transcript interaction networks, usually calculated as undirected maps, where genes are connected when a large co-expression connection occurs between them. 


\subsection{Co-expression \& physical interaction.}

Co-expression networks could be used to integrate unidentified function genes with biological processes, to coordinate genes for rival disease, or to track programmed gene expression regulations. Co-expression networks are interpreted by calculating co-expression values on a pair-related score of gene interaction and defining a significance level from information on gene expression. Discussions on standardization methods, co-expression similarity, meaning, and significance are still alive and ongoing. Trends in this sector included the combination of co-expression evaluation with separate omics methodologies, such as metabolomics, to determine the scheduled behavior between gene expression and metabolites, and to evaluate metabolite-regulated genetic networks among different methodologies [16].

\section{Results and Discussion}

\subsection{Gene collection.}

The liable genes for specific diseases retrieved from the NCBI database. The outcome shows respectively 37, 1101, 32 and 45 liable genes for AD, DE, ED and MD. There are 34 for $\mathrm{AD}, 537$ for $\mathrm{DE}, 30$ for $\mathrm{ED}$ and 42 for MD since processioning and sorting the associated genes for Homo sapiens. The genes are sorted in ascending order by their weight. The numerical values of identified liable genes are shown in Table 1.

\subsection{Gene mining, linkage \& common gene finding.}

It identifies the linkages between $\mathrm{AD}$ and $\mathrm{DE}, \mathrm{AD}$ and $\mathrm{ED}, \mathrm{AD}$ and $\mathrm{MD}, \mathrm{DE}$ and $\mathrm{ED}$, $\mathrm{DE}$ and $\mathrm{MD}, \mathrm{ED}$ and $\mathrm{MD}, \mathrm{AD}$ and $\mathrm{DE}$ and $\mathrm{ED}, \mathrm{AD}$ and $\mathrm{DE}$ and $\mathrm{MD}, \mathrm{AD}$ and $\mathrm{ED}$ and $\mathrm{MD}$, $\mathrm{DE}$ and $\mathrm{ED}$ and $\mathrm{MD}, \mathrm{AD}$ and $\mathrm{DE}$ and $\mathrm{ED}$ and $\mathrm{MD}$. The numbers of common liable genes are discovered between 4 selected diseases after gene linkage. The 4 weighted genes are kept to avoid complicated results [20]. The 4 weighted genes are SLC6A4, BDNF, COMT, DRD2. Figure 2 indicates the Venn analysis of the number of gene and the common gene ratio. The genes are extracted from the trusted database at the beginning of this research. After that, the data set was applied to the mining algorithm. In addition, there has been a rigorous analysis of the intersection of two, three and four diseases. We placed 34 no of gene for AD, 537 no gene for DE, 30 no gene for ED and 42 no gene for MD in the Venn diagram study. After Venn analysis, we get $16+6+4+4=30$ no of common gene between AD \& DE; $6+4=10$ no of common gene between AD\& ED; 4+4=8 no of common gene between AD\& MD; $6+9+4+1=20$ no of common gene between DE \& ED; $4+1+4+16=25$ no of common gene between DE \& MD; $4+1=5$ no of common gene between ED \& MD; 6+4=10 no of common gene between AD \& $\mathrm{DE} \& \mathrm{ED} ; 4+4=8$ no of common gene between AD \& DE \& MD; 4 no of common gene between $\mathrm{AD} \& \mathrm{ED} \& \mathrm{MD} ; 1+4=5$ no of common gene between DE \& ED \& MD; For AD \& DE \& ED $\&$ MD we get 4 no of common gene between them. Table 2 and Figure 2 reflect with each other after the investigation, so our study has been verified.

\subsection{Generic PPI.}

ToppGene is a comprehensive internet tool designed to enable committee researchers to perform routine and complex meta-examinations of data on gene expression using a natural web interface [17]. The PPI network is the link between genes and hub protein that are directly linked to others that are indirectly linked to each other. XGMML files are generated using the 
ToppGene web-based platform using the network-based k-Step Markov prioritization approach for the network diagram. By using XGMML file in Cytoscape, we develop the network and represent it in Figure 3 for selected 4 genes.

\subsection{Enrichment Analysis.}

In this paper, we propose a flexible and powerful framework for mining regional imaging genetic associations via voxel wise enrichment analysis, which embraces the collective effect of weak voxel-level signals and integrates brain anatomical annotation information [11]. WebGestalt (WEB-based Gene SeT AnaLysis Toolkit) is a functional enrichment analysis web tool [18]. By using WeGestalt tool, we select Network Topologybased analysis (NTA) as Method of Interset and also used network-based PPI BIOGRID as Functional Database for Homo sapiens for responsible 4 genes (SLC6A4, BDNF, COMT, DRD2). Figure 4 represents the enriched GO terms Graphs.

\subsection{Enrichment analysis.}

We have 4 genes responsible for building to establish genetic activity and pathways (SLC6A4, BDNF, COMT, DRD2). GeneMANIA is one of the most commonly available online tools in the linked gene network to predict gene function [19]. Figure 5 and Figure 6 , respectively, show the co-expression and physical interaction using the GeneMANIA tool. STRING database provides a network to show the direct links between the 4 genes responsible for the 4 diseases targeted. STRING is a web-based method for the interaction of genes with other molecular biology's [20]. The direct interaction between 4 genes is shown in Figure 12.

\subsection{Gene regulatory network.}

Gene regulatory networks vary from stronger-known communication networks between proteins and proteins, as two-party and lateral gene regulatory networks. To describe the gene regulatory network, we used web-based NetworkAnalyst tools. There are three types of gene regulatory network: Gene-miRNA interaction, TF-gene interaction, TF-miRNA coregulatory network [21-22]. Gene-miRNA interaction, TF-gene interaction, TF-miRNA coregulatory network are shown in Figure 7, Figure 8, and Figure 9, respectively.

\subsection{Protein drug interaction.}

Structural and mechanical assessment of the protein target during drug development is an important issue, preferably coupled with a multi-level understanding of how ligand binding modulates conformation and biological function [23]. By interacting with other proteins and ligands, proteins perform their roles in the cell. The complete set of drugs that can be used for the above selected disease is shown in Figure 10 PDI. The NetworkAnalyst tool generated PDI network and developed by Cytoscape.

\subsection{Protein chemical interaction.}

Biochemical networks are now helping to initiate a number of important human behavior research and disease prevention [24]. Interactions between proteins and small molecules are an integral part of biological processes in living organisms [25]. Figure 11 shows a protein-chemical interaction. The PCI is generated using the NetworkAnalyst tool. Finally, it 
can say that the analysis of gene regulatory netwrok or drug-protien interaction netwrok of this work like the articles $[26,27]$ will be most helpful for design future computational drug model $[28,29]$.

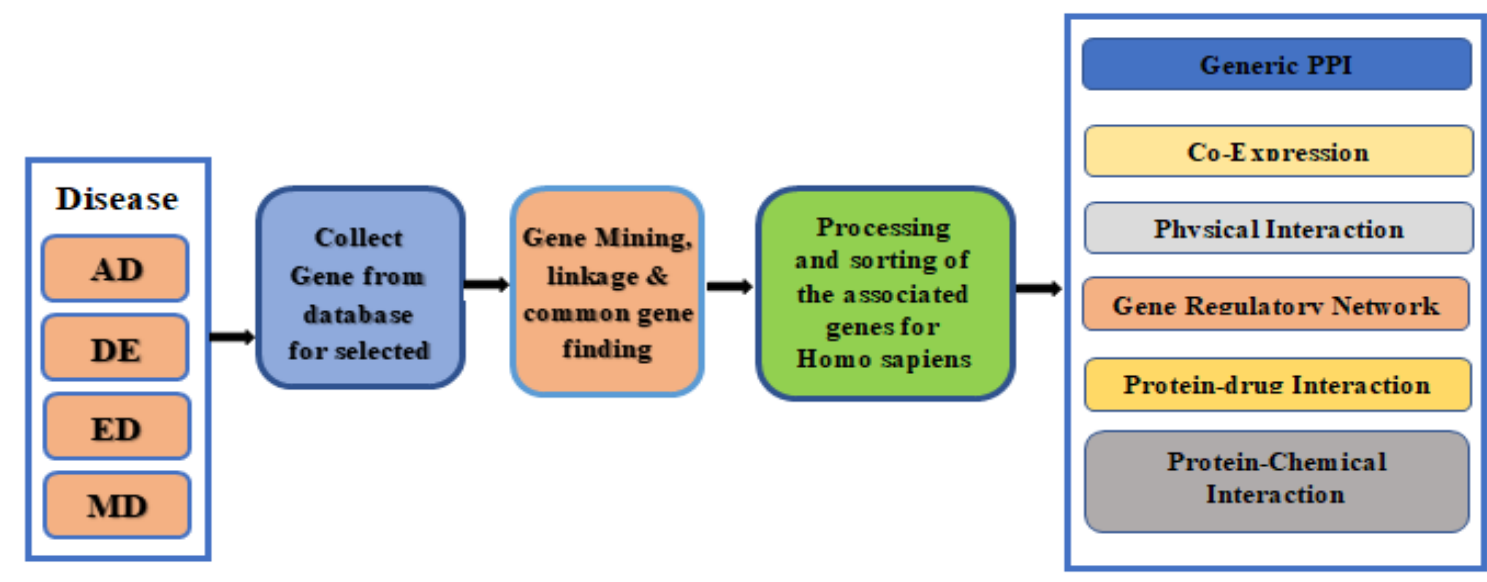

Figure 1. Flowchart of the Methodology offered.

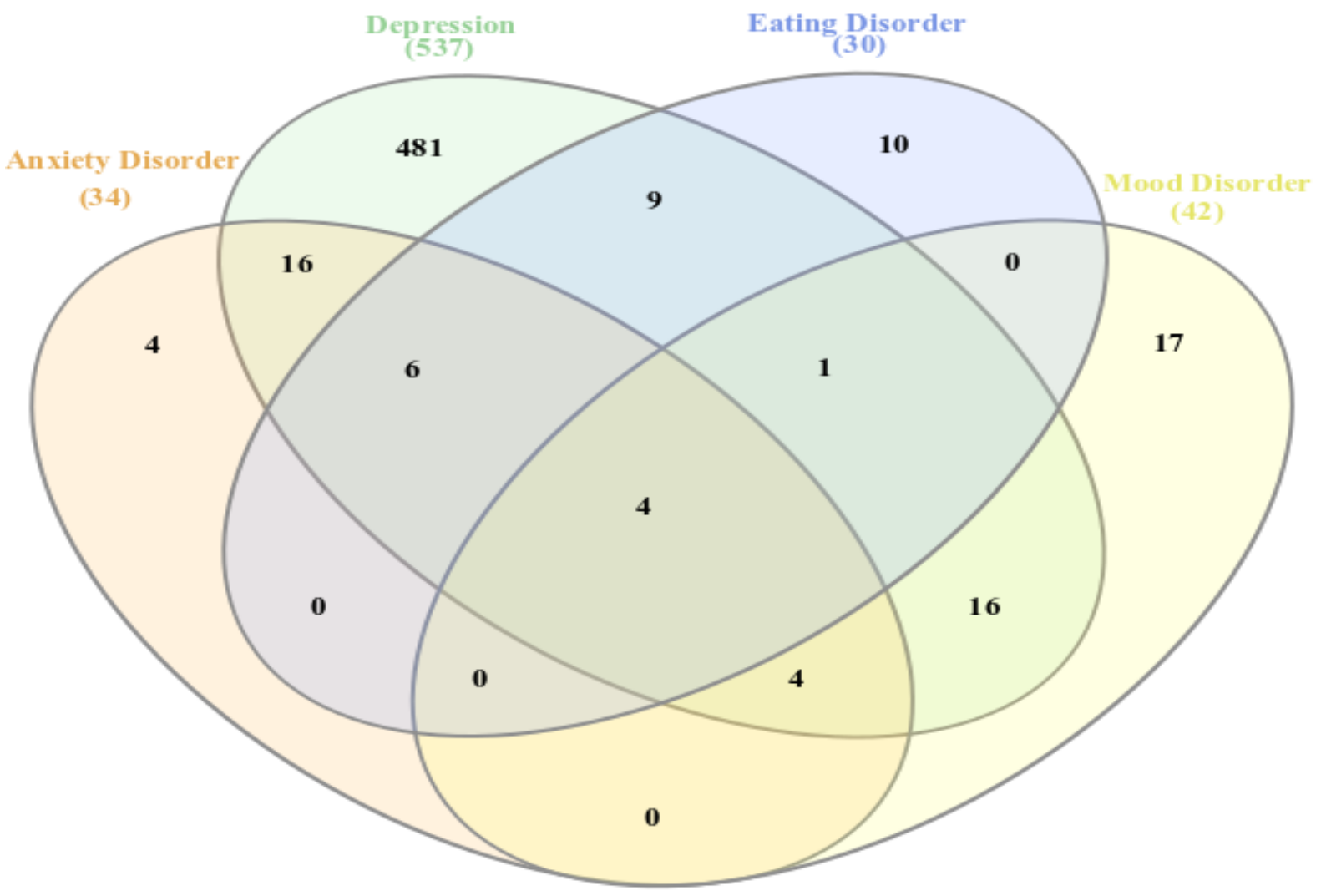

Figure 2. Venn diagram for selected 4 diseases. 


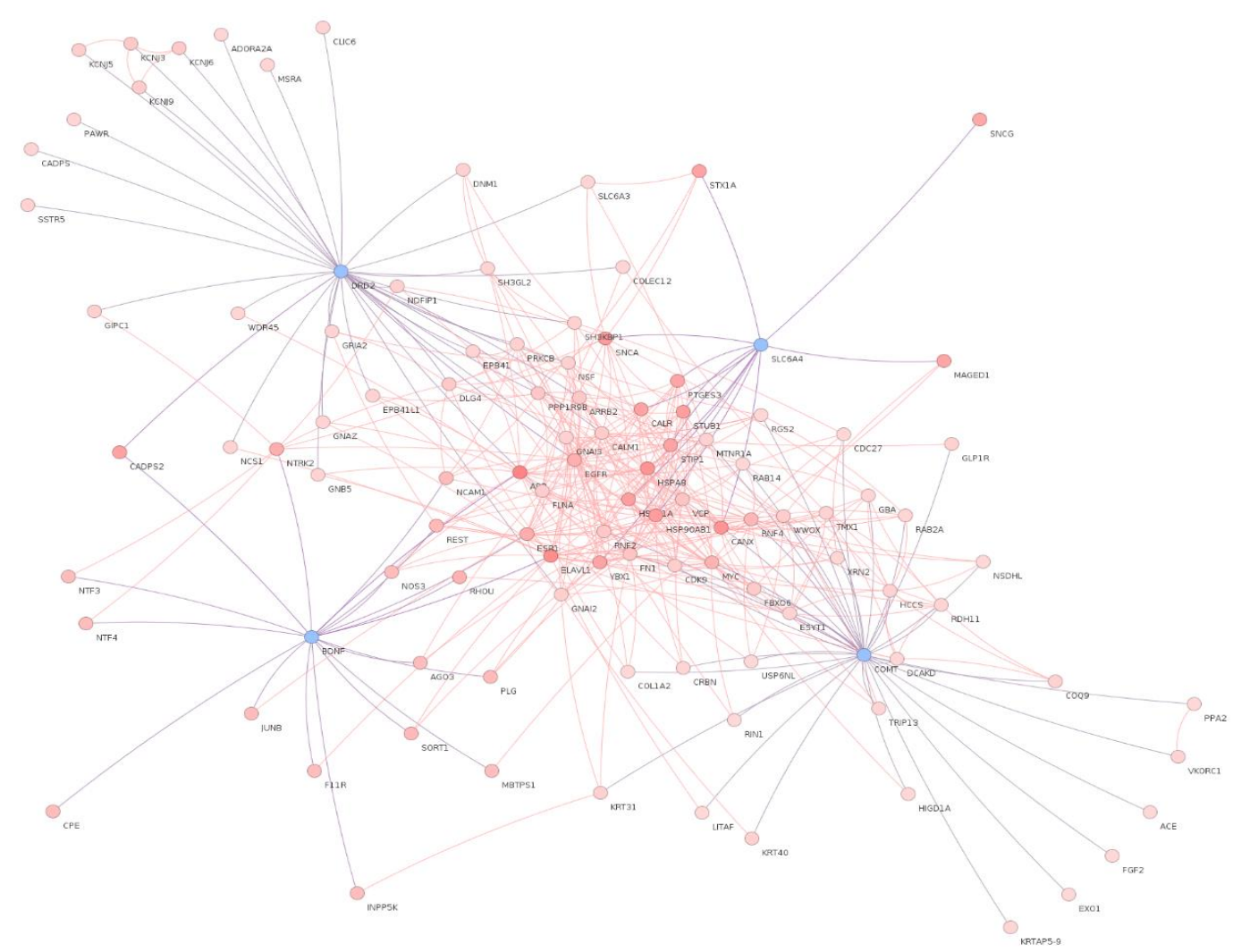

Figure 3. A network of 4 common responsible genes for PPI. There are 108 nodes and 440 edges to be built in the network. Nodes are proteins, and the edges establish a relationship between proteins.

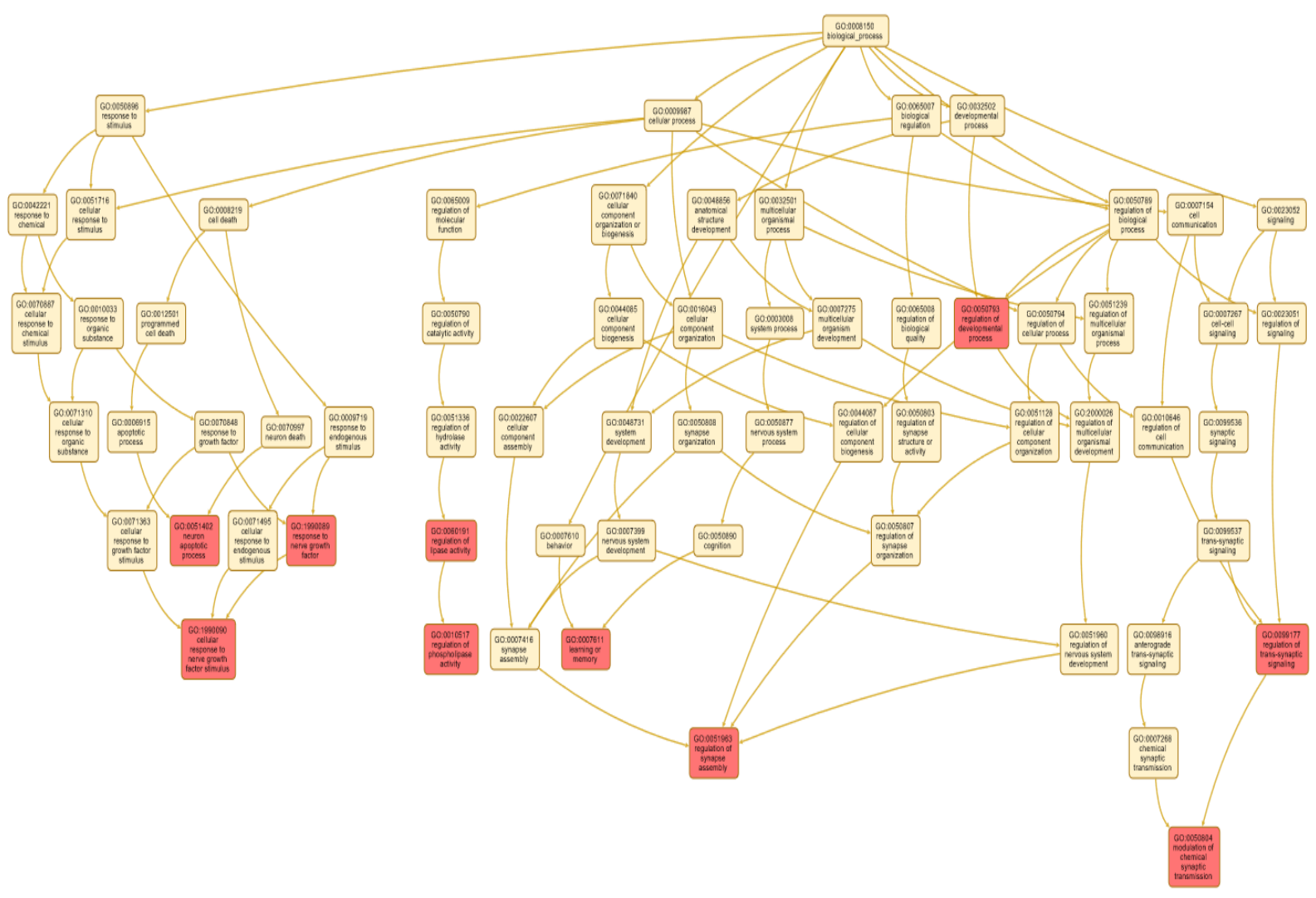

Figure 4. Enriched GO terms Graphs. 


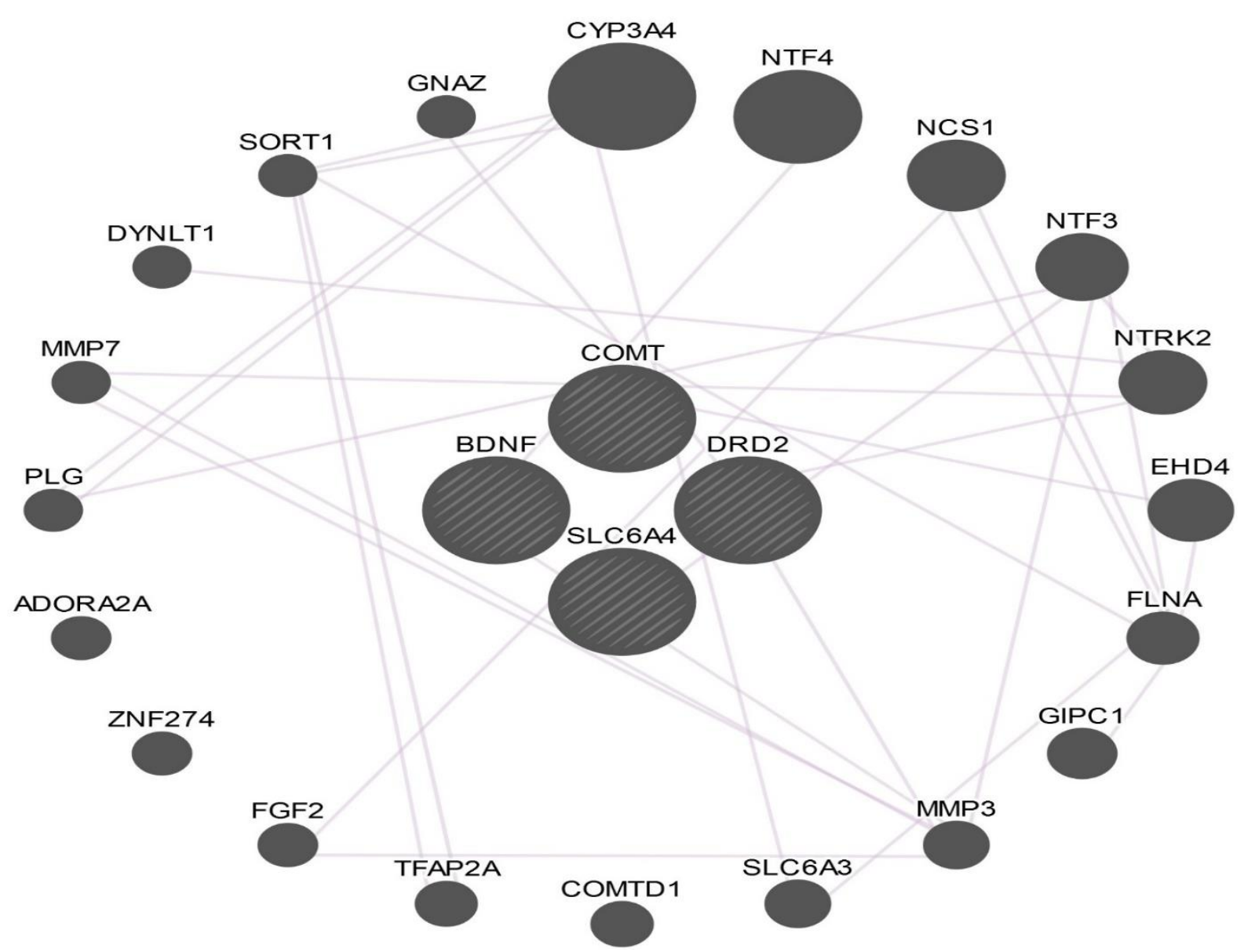

Figure 5. Co-expression between SLC6A4, BDNF, COMT, DRD2.

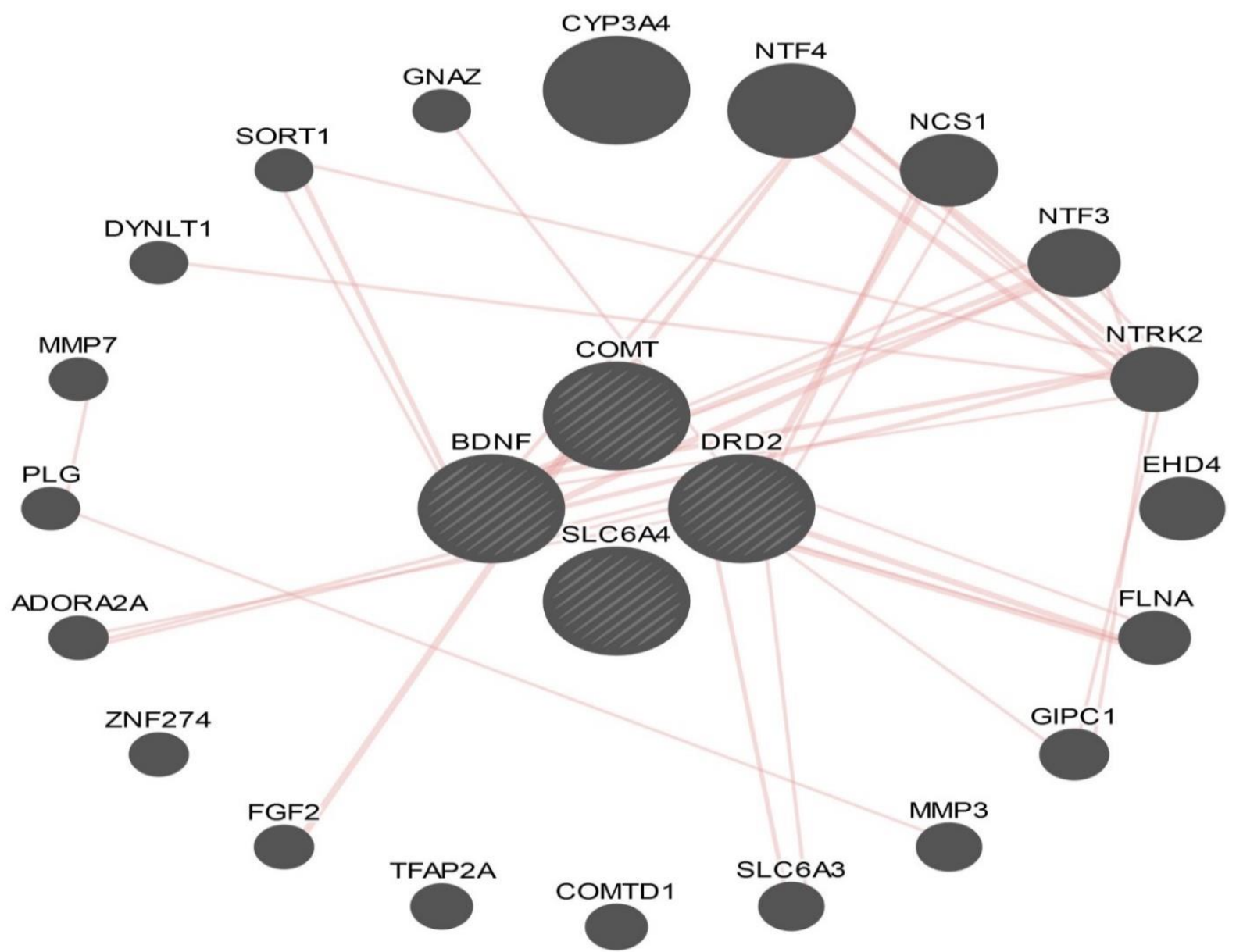

Figure 6. Physical Interaction between SLC6A4, BDNF, COMT, DRD2. 


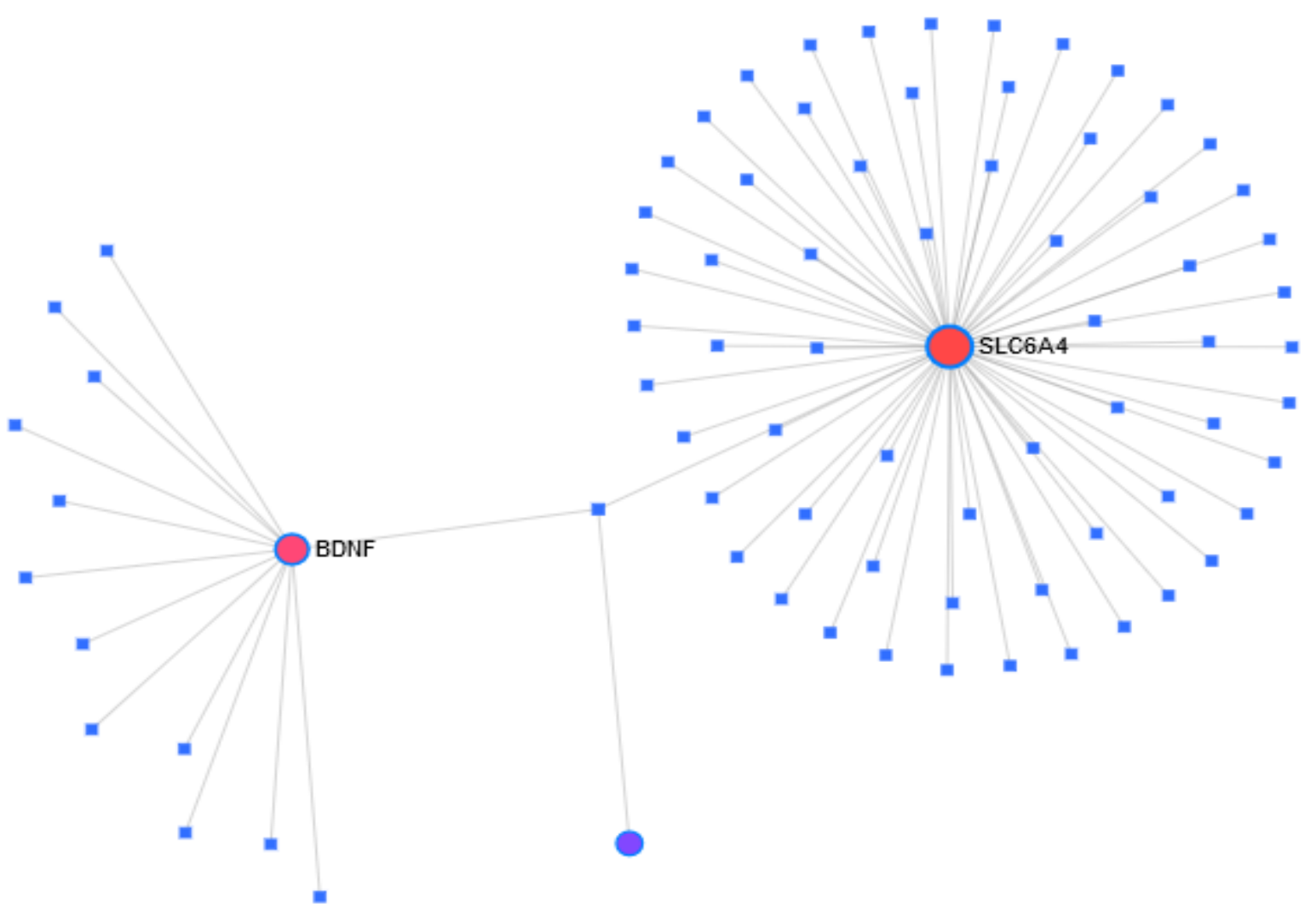

Figure 7. Gene -miRNA Interaction for selected 4 genes. This gene-miRNA interaction generates interactions with a total of 78 links between 79 genes.

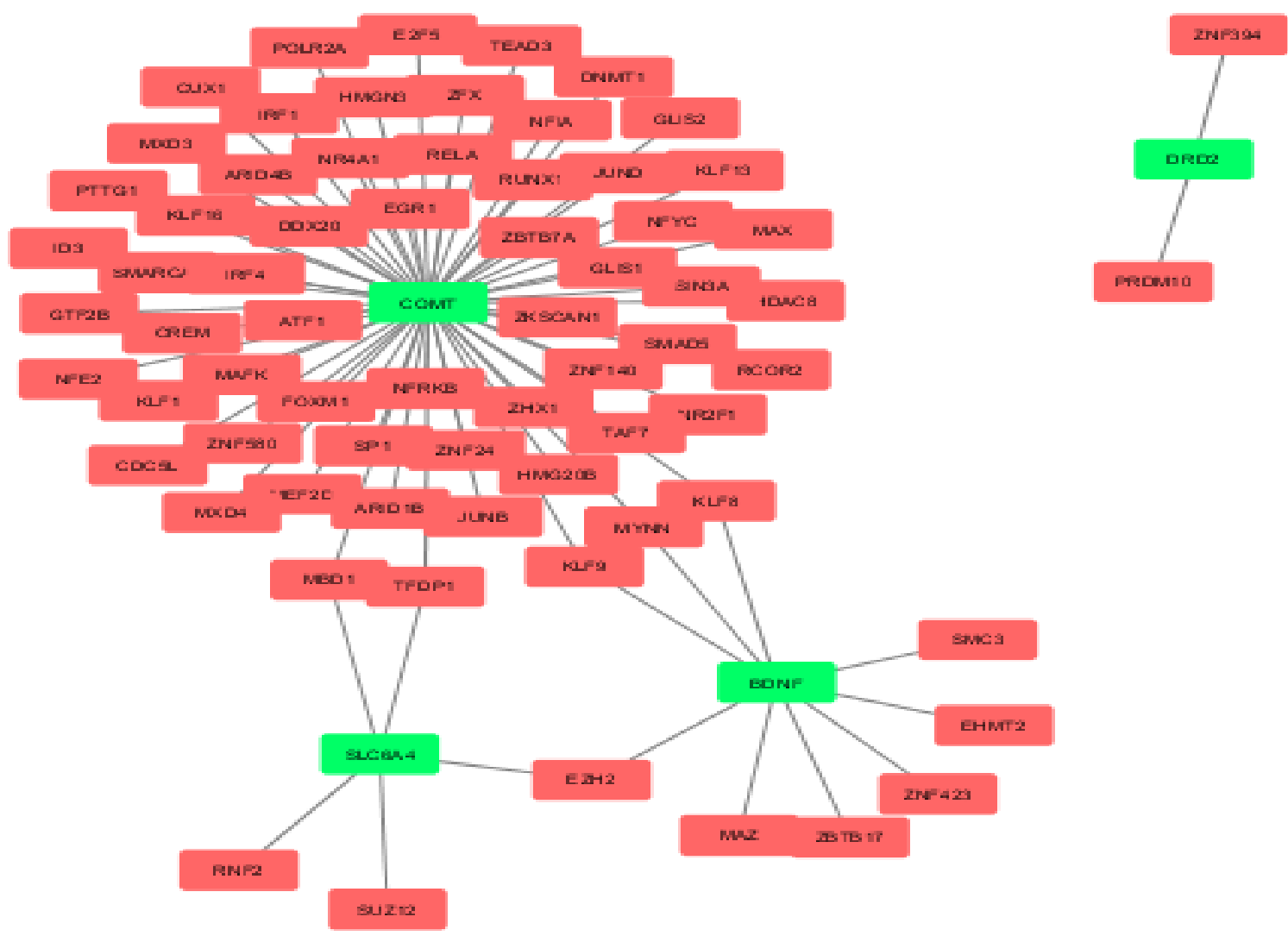

Figure 8. TF-gene Interaction for selected 4 genes. This TF-gene Interaction creates relationships between 73 proteins with a total of 75 connections. 


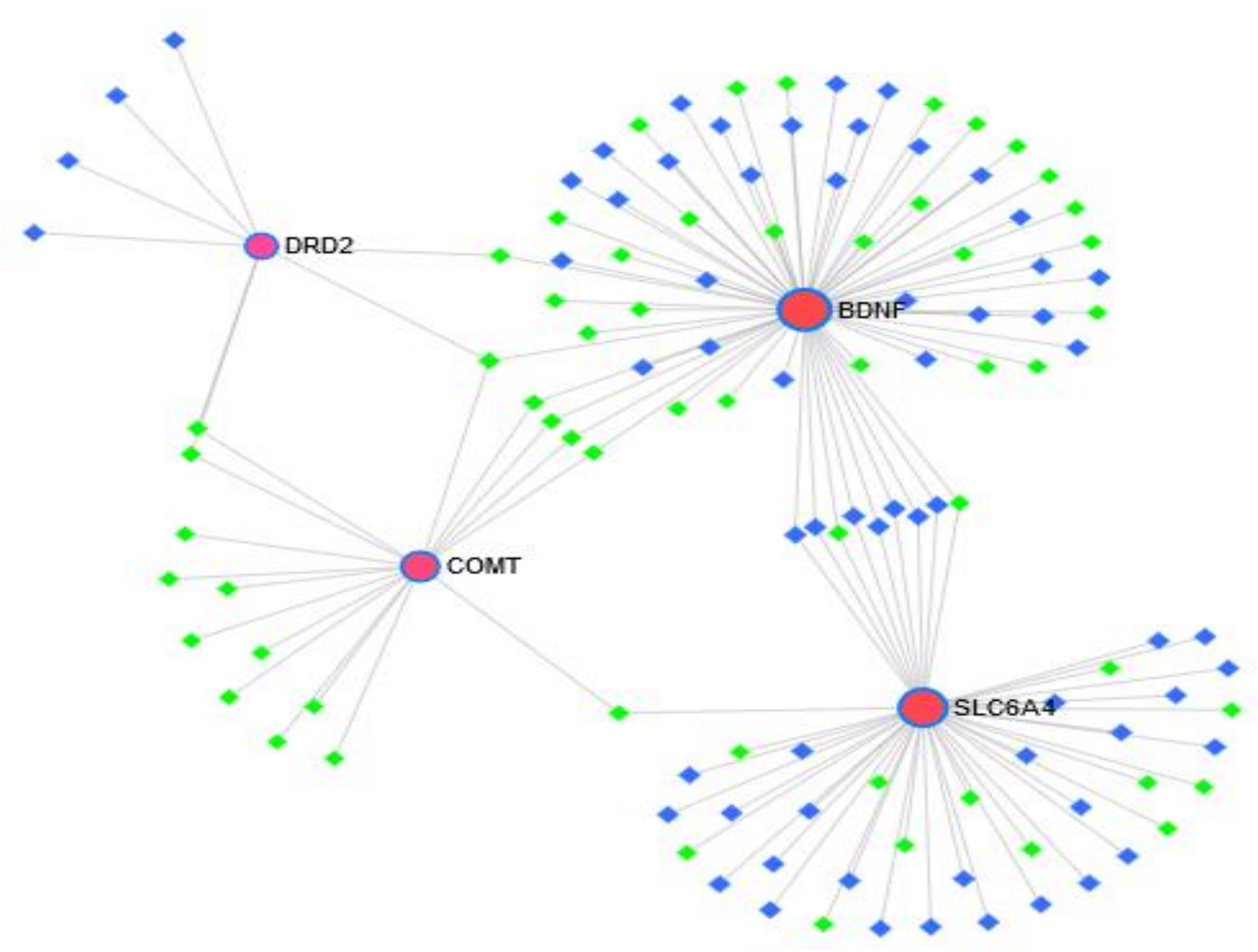

Figure 9. TF-miRNA co-regulatory network for selected 4 genes. This TF-miRNA coregulatory network creates relationships between 3678 proteins with a total of 4530 connections.

Table 1. The number of responsibility genes for selected diseases obtained from the NCBI database.

\begin{tabular}{c|c|c} 
Diseases Name & Total no of gene & Total no of Homo sapiens \\
\hline Anxiety Disorder (AD) & 37 & 34 \\
\hline Depression (DE) & 1101 & 537 \\
\hline Eating Disorder (ED) & 32 & 30 \\
\hline Mood Disorder (MD) & 45 & 42
\end{tabular}

Table 2. The no of common gene between selected 4 diseases during the intersection process.

\begin{tabular}{c|c|c|} 
Disease & Total no. of gene & Common gene \\
\hline AD \& DE & 571 & 30 \\
\hline AD \& ED & 64 & 10 \\
\hline AD \& MD & 76 & 8 \\
\hline DE \& ED & 567 & 20 \\
\hline DE \& MD & 579 & 25 \\
\hline ED \& MD & 72 & 5 \\
\hline AD \& DE \&ED & 601 & 10 \\
\hline AD \& DE \& MD & 613 & 8 \\
\hline AD \& ED \& MD & 106 & 4 \\
\hline DE \& ED \& MD & 609 & 5 \\
\hline AD \& DE \& ED \& MD & 643 & 4
\end{tabular}




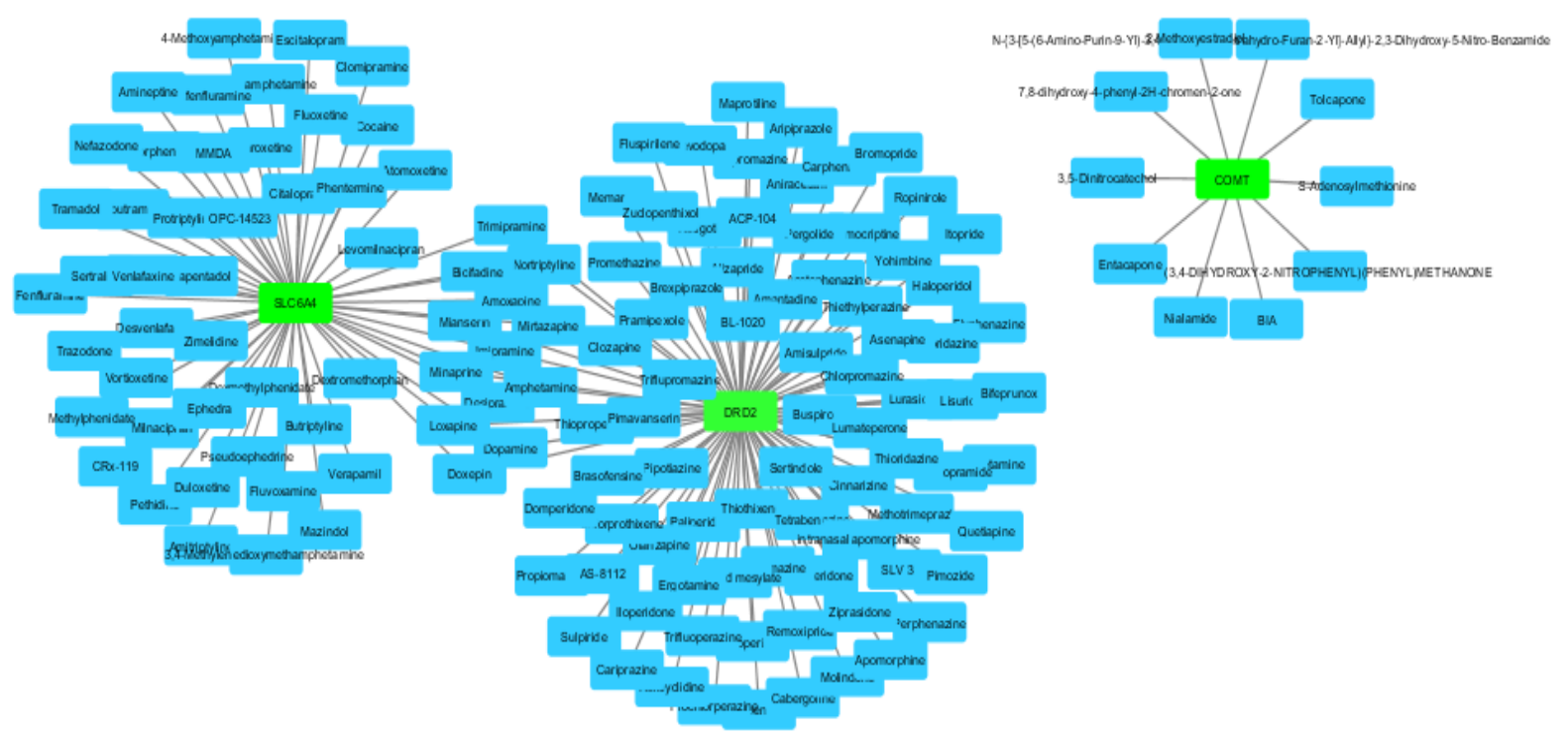

Figure 10. Protein-drug interaction for selected 4 genes. This PDI creates relationships between 147 proteins with a total of 157 connections.

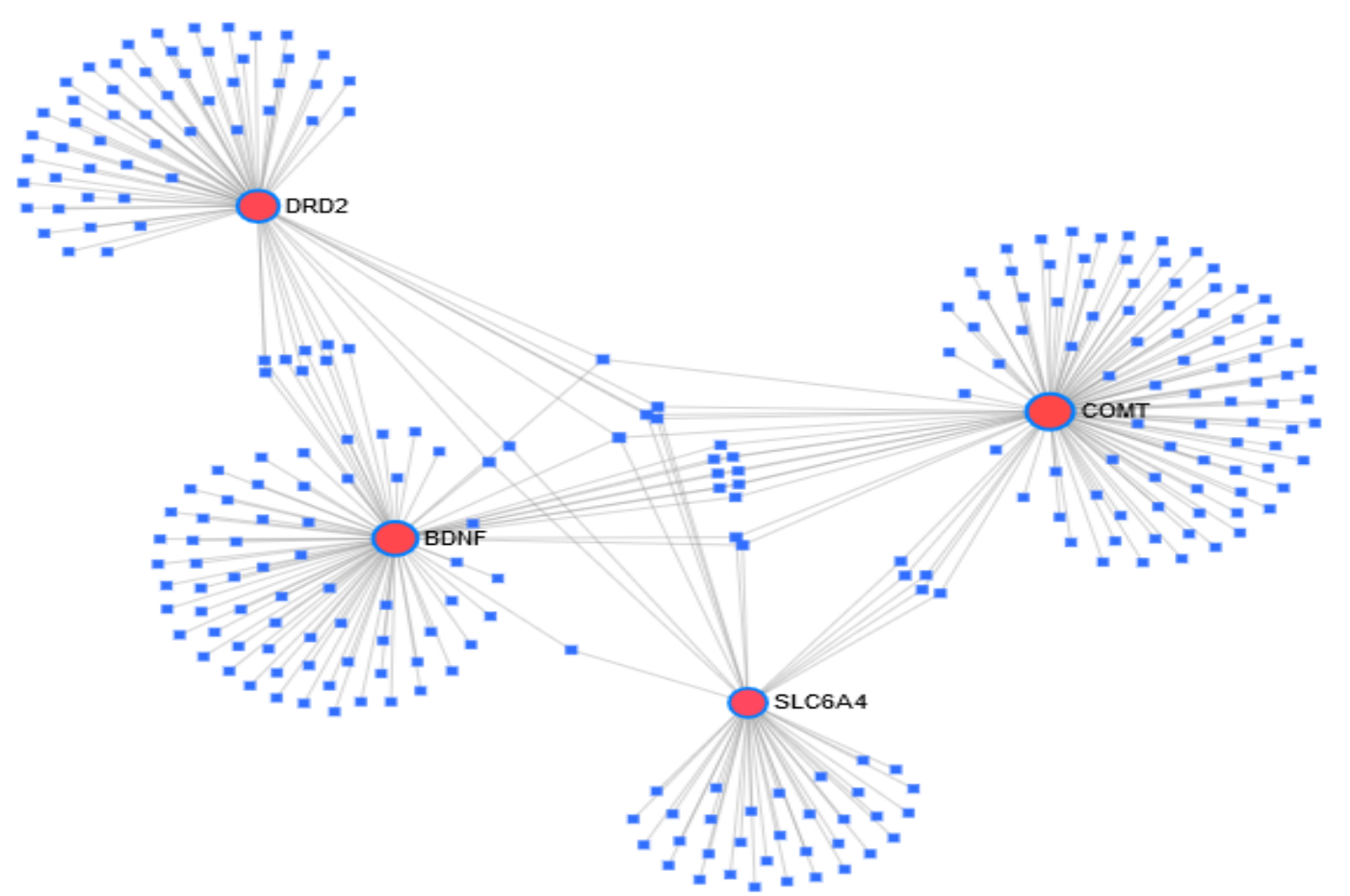

Figure 11. Protein-chemical interaction for selected 4 genes. This PDI creates relationships between 273 proteins with a total of 309 connections.

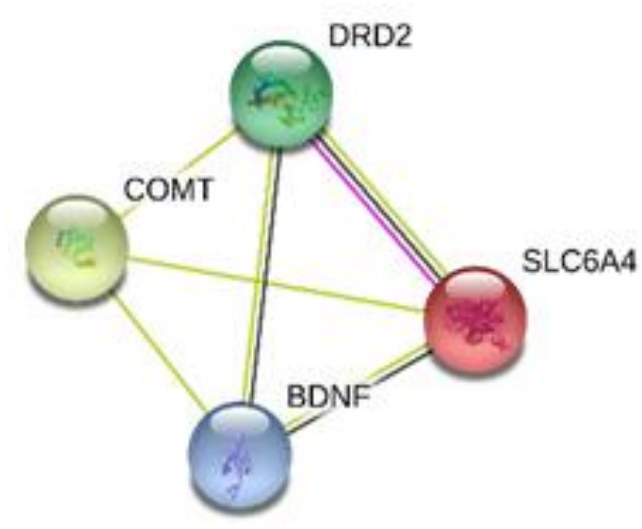

Figure 12. Connecting 4 genes (SLC6A4, BDNF, COMT, DRD2) using the STRING database. The network demonstrates the common genes inter relationship. 


\section{Conclusions}

We have presented an overview of four disease: AD, DE, ED and MD. Crossconnection of mental illeness demonstrates the relationship between them at the gene level. In the so-called "Post-genomic Era," one of the most interesting and important problems is the interpretation of protein networks. Most of our understanding of drugs, drug pathways and drug receptors could fit into a few encyclopedic books and a few hundred schematic figures until the 1980s. Moreover, this is no longer the case with the recent explosion in biological and chemical information. The creation of medicine-binding databases plays a crucial role in understanding the relationship between protein and drug interaction [30]. Enhancements to the bioinformatics platform have demonstrated new field of study and created uncompromising tasks simpler than before. From these study results of the related susceptible genes between linked diseases, it will be useful to investigate both the diseases and the accurate design of drugs. This research also helps to understand the PPI, the regulatory gene network, the proteindrug interaction, and the protein-chemical interaction. The purpose of this study is to understand the network of genes for metabolism and to improve drug design.

\section{Funding}

This research received no external funding.

\section{Acknowledgments}

The authors are grateful who have participated in this research work.

\section{Conflicts of Interest}

The authors declare no conflict of interest.

\section{References}

1. Islam, M.R.; Ahmed, M.L.; Paul, B.K.; Bhuiyan, T.; Ahmed, K. Potential therapeutic drugs for ischemic stroke and stress disorder: A bioinformatics analysis. Informatics in Medicine Unlocked 2019, 17, https://doi.org/10.1016/j.imu.2019.100259

2. Diagnostic and Statistical Manual of Mental Disorders American Psychiatric Association (5th ed.). Arlington: American Psychiatric Publishing. 2013; pp. 189-195.

3. World Health Organization https://www.who.int/health-topics/depression\#tab=tab_1, Last Access: 22.12.2019.

4. Santonicola, A.; Gagliardi, M.; Guarino, P.M.; Siniscalchi, M.; Ciacci, C.; Iovino, P. Eating Disorders and Gastrointestinal Diseases. Nutrients 2019, 11, https://doi.org/10.3390/nu11123038.

5. Lewinsohn, P.M.; Hyman, H.; Roberts, R.E.; Seeley, J.R.; Andrews, J.A. "dolescent psychopathology: I. Prevalence and incidence of depression and other DSM-III-R disorders in high school students. Journal of abnormal psychology 1993, 102, https://doi.org/10.1037/0021-843X.102.1.133.

6. American Psychiatric Association. Association, AP Diagnostic and statistical manual of mental disorders. Arlington, VA, US. 1995.

7. Hetterich, L.; Mack, I.; Giel, K.E.; Zipfel, S.; Stengel, A. An update on gastrointestinal disturbances in eating disorders. Molecular and Cellular Endocrinology 2019, 497, https://doi.org/10.1016/j.mce.2018.10.016

8. Rakofsky, J.; Rapaport, M. Mood Disorders. CONTINUUM: Lifelong Learning in Neurology 2018, 24, 804827.

9. Lee, H.J.; Kim, S.H.; Lee, M.S. Understanding Mood Disorders in Children. In: Frontiers in Psychiatry: Artificial Intelligence, Precision Medicine, and Other Paradigm Shifts. Kim, Y.K. Ed. Springer Singapore: Singapore, 2019; pp. 251-261 https://doi.org/10.1007/978-981-32-9721-0_12

10. Shannon, P.; Markiel, A.; Ozier, O.; Baliga, N.S.; Wang, J.T.; Ramage, D.; Amin, N.; Schwikowski, B.; Ideker, T. Cytoscape: a software environment for integrated models of biomolecular interaction networks. Genome Res 2003, 13, 2498-2504, https://doi.org/10.1101/gr.1239303. 
11. Yao, X.; Cong, S.; Yan, J.; Risacher, S.L.; Saykin, A.J.; Moore, J.H.; Shen, L. Regional imaging genetic enrichment analysis. Bioinformatics 2020, 36, 2554-2560, https://doi.org/10.1093/bioinformatics/btz948.

12. Taz, T.A.; Kawsar, M.; Paul, B.K.; Ahmed, K. Computational analysis of regulatory genes network pathways among devastating cancer diseases. Journal of Proteins and Proteomics 2020, 11, 63-76, https://doi.org/10.1007/s42485-020-00032-z

13. Hasan, M.R.; Paul, B.K.; Ahmed, K.; Bhuyian, T. Design protein-protein interaction network and proteindrug interaction network for common cancer diseases: A bioinformatics approach. Informatics in Medicine Unlocked 2020, 18, https://doi.org/10.1016/j.imu.2020.100311

14. Wang, C.; Kurgan, L. Survey of Similarity-based Prediction of Drug-protein Interactions. Curr Med Chem 2019, https://doi.org/10.2174/0929867326666190808154841.

15. Kuhn, M.; Szklarczyk, D.; Franceschini, A.; von Mering, C.; Jensen, L.J.; Bork, P. STITCH 3: zooming in on protein-chemical interactions. Nucleic Acids Res 2011, 40, D876-D880, https://doi.org/10.1093/nar/gkr1011

16. Tieri, P.; Farina, L.; Petti, M.; Astolfi, L.; Paci, P.; Castiglione, F. Network Inference and Reconstruction. In: Bioinformatics. 2019; pp. 805-813.

17. Chen, J.; Aronow, B.J.; Jegga, A.G. Disease candidate gene identification and prioritization using protein interaction networks. BMC Bioinformatics 2009, 10, https://doi.org/10.1186/1471-2105-10-73

18. Wang, J.; Duncan, D.; Shi, Z.; Zhang, B. WEB-based GEne SeT AnaLysis Toolkit (WebGestalt): update 2013. Nucleic Acids Res 2013, 41, W77-W83, https://doi.org/10.1093/nar/gkt439

19. Warde-Farley, D.; Donaldson, S.L.; Comes, O.; Zuberi, K.; Badrawi, R.; Chao, P.; Franz, M.; Grouios, C.; Kazi, F.; Lopes, C.T.; Maitland, A.; Mostafavi, S.; Montojo, J.; Shao, Q.; Wright, G.; Bader, G.D.; Morris, Q. The GeneMANIA prediction server: biological network integration for gene prioritization and predicting gene function. Nucleic Acids Res 2010, 38, W214-W220, https://doi.org/10.1093/nar/gkq537.

20. Berend, S.; Lehmann, G.; Bork, P.; Huynen, M.A. STRING: a web-server to retrieve and display the repeatedly occurring neighbourhood of a gene. Nucleic acids research 2000, 28, 3442-3444.

21. Conte, F.; Fiscon, G.; Licursi, V.; Bizzarri, D.; D'Antò, T.; Farina, L.; Paci, P. A paradigm shift in medicine: A comprehensive review of network-based approaches. Biochimica et Biophysica Acta (BBA) - Gene Regulatory Mechanisms 2020, 1863, https://doi.org/10.1016/j.bbagrm.2019.194416

22. Gov, E.; Arga, K.Y. Interactive cooperation and hierarchical operation of microRNA and transcription factor crosstalk in human transcriptional regulatory network. IET Syst Biol 2016, 10, 219-228, https://doi.org/10.1049/iet-syb.2016.0001.

23. Eyers, C.E.; Vonderach, M.; Ferries, S.; Jeacock, K.; Eyers, P.A. Understanding protein-drug interactions using ion mobility-mass spectrometry. Current Opinion in Chemical Biology 2018, 42, 167-176, https://doi.org/10.1016/j.cbpa.2017.12.013

24. Barabási, A.-L.; Gulbahce, N.; Loscalzo, J. Network medicine: a network-based approach to human disease. Nature Reviews Genetics 2011, 12, 56-68, https://doi.org/10.1038/nrg2918.

25. Szklarczyk, D.; Santos, A.; von Mering, C.; Jensen, L.J.; Bork, P.; Kuhn, M. STITCH 5: augmenting protein-chemical interaction networks with tissue and affinity data. Nucleic Acids Res 2015, 44, D380-D384, https://doi.org/10.1093/nar/gkv1277

26. Monajjemi, M. Molecular biology's symphony orchestra from DNA to ribosome: a sonification from gene to protein. Biointerface Research in Applied Chemistry 2020, 10, 5679-5688, https://doi.org/10.33263/BRIAC104.679688

27. Ahmed, M.L.; Islam, M.R.; Paul, B.K.; Ahmed, K.; Bhuyian T. Computational modeling and analysis of gene regulatory interaction network for metabolic disorder: a bioinformatics approach. Biointerface Research in Applied Chemistry 2020, 10, 5910-5917, https://doi.org/10.33263/BRIAC104.910917

28. Chaudhary, S.; Majhi, S.; Verma M. Biomarkers for epilepsy - a new ray of hope. Letters in Applied NanoBioScience 2020, 9, 830-839, https://doi.org/10.33263/LIANBS91.830839

29. Geetanjali; Sharma, P.K.; Malviya, R. Toxicity and application of nano-silver in multi-drug resistant therapy. Letters in Applied NanoBioScience 2020, 9, 824-829, https://doi.org/10.33263/LIANBS91.824829

30. de Azevedo, W.F., Jr.; Dias, R. Experimental approaches to evaluate the thermodynamics of protein-drug interactions. Curr Drug Targets 2008, 9, 1071-1076, https://doi.org/10.2174/138945008786949441. 